\title{
PEST Analysis Model dalam Pengembangan Potensi Wisata Pulau Benan, Kabupaten Lingga, Kepulauan Riau
}

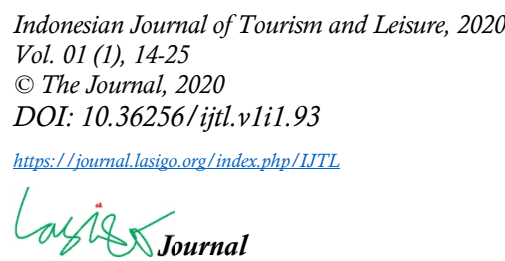

Article History

Received: April $3^{\text {rd }}, 2020$

Revised: April 14 ${ }^{\text {th }}, 2020$

Accepted : April 15 $5^{\text {th }}, 2020$

\section{Mahadiansar}

Pascasarjana Ilmu Administrasi Publik, Fakultas Ilmu Administrasi, Universitas Brawijaya, Malang, Jawa Timur mahadiansar@student.ub.ac.id

\section{Aspariyana}

Program Studi Sosiologi, FISIP, Universitas Maritim Raja Ali Haji, Kota Tanjungpinang, KEPRI

riyanaaspa@gmail.com

\begin{abstract}
The core problem of tourism sector on empowerment and natural resource development is the mapping to the potency and development strategy of tourism has not yet been maximized. This article, focus to use the PEST Model analysis to identify the growth of Benan Island as tourism destination. This research conducted through library study, and data analyzed through content analysis. The result, political, economic, social and technology factors has impacted broadly to development of Benan Island tourism in the long run. The author also purpose the alternatif model of development of priority scale tourism potential with the concept of sustainable tourism and community empowerment by involving tourism industry actors. The use of PEST Model Analysis of the tourism potential of Benan Island can also be applied to several other islands in Lingga Regency.
\end{abstract}

Keywords: PEST Analysis Model, Tourism Development, Tourism Potency, Tourism Island

\begin{abstract}
ABSTRAK
Permasalahan utama sektor pariwisata dalam pemberdayaan dan pengembangan Sumber Daya Alam adalah belum maksimalnya pemetaan terhadap potensi dan strategi pengembangan pariwisata. Tulisan ini fokus penggunaan PEST Analysis Model untuk mengindentifikasi perkembangan potensi Pulau Benan sebagai destinasi wisata. Penelitian mengunakan metode studi kepustakaan dengan teknik analisis data menggunakan content analysis. Hasil penelitian menunjukan bahwa faktor politik, ekonomi, sosial dan teknologi sangat besar pengaruhnya terhadap potensi pengembangan pariwisata Pulau Benan dalam waktu jangka panjang. Selain itu peneliti juga memberikan alternatif model pengembangan potensi pariwisata skala prioritas dengan konsep pariwisata berkelanjutan dan pemberdayaan masyarakat dengan melibatkan pegiat industri pariwisata. Penggunaan PEST Analisis Model terhadap potensi pariwisata Pulau Benan bisa juga bisa diterapkan terhadap beberapa pulau lain yang ada di Kabupaten Lingga.
\end{abstract}

Kata Kunci: Model Analisis PEST, Pengembangan Wisata, Potensi Pariwisata, Wisata Kepualuan

Corresponding Author

Name : Mahadiansar

Email : mahadiansar@student.ub.ac.id 


\section{Pendahuluan}

Di Indonesia, sektor pariwisata memiliki kekayaan sumber daya alam yang besar karena bagian dari sebuah negara kepulauan. Pengelolaan dan perkembangan sektor pariwisata juga meningkat pada setiap tahunnya. Sebagaimana muncul pada laporan World Tourism Organization (WTO) pada tahun 2018, berdasarkan kunjungannya sebanyak 15.810 .305 pengunjung dari penjuru dunia yang datang ke indonesia. Salah satu penyebabnya tingginya kunjungan wisatawan asing ke indonesia adalah pengembangan pariwisata halal yang menjadi salah satu branding indonesia (Widagdyo, 2015; Widhasti et al, 2017), memegang konsep pariwisata yang berkelanjutan (Hengky \& Kikvidze, 2018) dan menciptakan strategi melalui branding dengan keterlibatan pihak swasta bekerjasama pegiat industri pariwisata (Nuzululita et al, 2020). Semakin meningkatnya sektor pariwisata di Indonesia tentunya akan berdampak terhadap potensi-potensi pariwisata baru yang masih belum dieksplorasi dengan baik dari berbagai wilayah yang selama ini belum bisa dikelola secara maksimal.

Realitas yang ada saat ini, keberhasilan sektor pariwisata tidak hanya diukur dengan indikator dan meningkatnya jumlah kunjungan pariwisata di Indonesia, namun juga dengan kelemahan yang terjadi diantaranya ketidakaturan aspek amenitas dan aksebilitas serta jaminan keamanan bagi wisatawan mancanegara berkunjung ke indonesia (Bachri, 2018). Hal ini terjadi pada destinasi wisata di daerah-daerah yang kurang diawasi oleh pemerintah pusat. Demi terwujudnya keamanan dan ketertiban pariwisata, diperlukan evaluasi pengelolaan destinasi wisata di daerah, terutama beberapa pulau yang ada di Indonesia dengan memperhatikan status sosial dan status ekologi di wilayah tersebut (Kurniawan, Adrianto, Bengen, \& Prasetyo, 2019).

Di berbagai wilayah Indonesia, sektor pariwisata memang cukup menjanjikan sebagai penyumbang devisa di masa depan (Firdaus, 2018). Hal ini karena baik pemerintah maupun swasta, mempunyai program yang memberikan dampak kemajuan suatu daerah, data menunjukan sebanyak 17 miliar USD penerimaan negara dari sektor pariwisata pada tahun 2018 dan diprediksi akan naik hingga mencapai 21 miliar USD (Thomas, 2019). Pada saat ini sektor pariwisata Indonesia sebagai penyumbang devisa terbesar, mengalami keterpurukan akibat penyebaran Coronavirus Disease (COVID-19). Akibat pandemi ini, Indonesia terancam kehilangan devisa sebesar 350 juta USD. Berdasarkan data Badan Perencanaan Pembangunan Nasional (BAPPENAS) Republik Indonesia (Anggita, 2020), pemerintah pusat maupun pemerintah daerah harus mencari alternatif-alternatif serta kebijakan secara bersama untuk menghidupkan kembali sektor pariwisata.

Pemerintah daerah yang memungkinkan untuk memiliki kemampuan mengoptimalisasi potensi terbaik yang dimilikinya dan mendorong daerah untuk berkembang sesuai dengan karakteristik dilingkungannya, baik internal maupun eksternal (Yoserizal \& Yudiatmaja, 2010). Provinsi Kepulauan Riau (KEPRI) yang dikenal pariwisata baharinya, pemerintah pusat dan daerah telah berupaya meningkatkan akses infrastruktur yang dikelola secara berkelanjutan, sehingga bisa diakses secara menyeluruh oleh wisatawan domestik dan wisata mancanegara (Karlina \& Iskandar, 2017). Keseriusan pemerintah daerah Provinsi KEPRI pengembangan sektor industri pariwisata bisa dilihat pada laporan Dinas Pariwisata KEPRI yang menunjukan sebanyak 2.590.802 kunjungan yang datang ke KEPRI melebihi target Rencana Pembangunan Jangka Menengah (RPJMD), yaitu 2,3 juta pengunjung. Artinya potensi pariwisata KEPRI sangat diminati oleh wisatawan mancanegara (Bintang, 2020). Oleh karena itu potensi pariwisata KEPRI harus dikelola dengan manajemen baik dan segala regulasi maupun aturan yang mengatur pariwisata demi terciptanya kenyamanan pariwisata sesuai dengan kebutuhan perkembangan zaman dari waktu ke waktu.

Beberapa peneliti sebelumnya tentang kapariwisataan di KEPRI telah dilakukan di beberapa daerah dengan berbagai pendekatan. Di Kabupaten Bintan menggunakan pengembangan potensi pariwisata dengan pendekatan politik dan pengembangan ekonomi (Marina, 2012), Kabupaten 
Karimun dalam pengembangan potensi pariwisata menggunakan analisis SWOT dengan hasil menunjukan bahwa mengembangkan potensi daya tarik wisata seperti (1) event-event wisata (2) meningkatkan partisipasi masyarakat terhadap kegiatan wisata yang dilakukan (3) menambah variasi objek daya tarik wisata yang lebih inovatif seperti olahraga air, outbond dan sebagainya, dan (4) memperbaiki kualitas aksesibilitas dan meningkatkan fasilitas wisata yang terdiri dari tempat peribadatan, sarana informasi dan juga keamanan (Tiara \& Darsiharjo, 2013). Penelitian di Kota Batam tentang potensi dan daya tarik wisata menggunakan konsep keterpaduan antara pulau ke pulau (integrasi) dalam pengembangan pariwisata dengan pendekatan rasionalitas (Nadjmi \& Prayitno, 2013). Penelitian di Kabupaten Lingga melihat pengembangan potensi pariwisata melalui promosi wisata pantai (Siam, 2015). Di Kabupaten Kepulauan Anambas, peneliti menggunakan konsep berbasis kemaritiman, dan dalam pengembangannya menggunakan pendekatan ekonomi masyarakat yang mengarah ke industri kepariwisataan kemaritiman (Arfandi \& Adhayanto, 2017). Kabupaten Natuna penelitian tentang pengembangan potensi dengan mengandalkan geowisata (Thariqy, Pristiwasa, \& Hakim, 2019).

Desa Pulau Benan merupakan salah satu desa yang berada dalam Kecamatan Senayang, Kabupaten Lingga memiliki potensi Wisata Bahari yang layak untuk dikembangkan menjadi wisata unggul di Provinsi KEPRI setelah Lagoi. KEPRI berhasil membukukan Rp 4,8 triliun dari industri pariwisata sepanjang tahun 2017 lalu. Berdasarkan hasil penelitian, pengembangan strategi pariwisata Desa Pantai Pulau Benan dapat dirumuskan dengan menggunakan SWOT dengan menerapkan Pariwisata Berbasis Masyarakat sebagai pendekatan pengembangan pariwisata (Akhirman \& Nurhasanah, 2019). Pembaharuan dari tulisan ini adalah peneliti ingin mengungkapkan potensi sektor pariwisata pulau-pulau yang ada di Pulau Benan Kabupaten Lingga dengan mengunakan teori oleh Ward \& Peppard (2002) yaitu model analisis PEST sebagai bentuk pendekatan dalam pengembangan potensi pariwisata.

Model ini sangat sukses sebagai bentuk analisa dalam menjangkau potensi Sumber Daya Manusia dan Sumber Daya Alam, baik di sektor swasta maupun sektor publik. Seperti studi analisis potensi bahwa model analisis PEST saling mempengaruhi terhadap potensi di lingkungannya serta faktor penunjang lainnya (Retnowati, 2010; Nofrizal, 2015; Sari et al., 2019). Model analisis PEST sudah banyak dilakukan beberapa negara seperti Singapura, Serbia, Malaysia, Paskitan dan Nigeria untuk berbagai bidang sektor dalam menganalisa potensi yang dianggap berpengaruh terthadap perekonomian negara (Ha \& Coghill, 2008; Stosic et al., 2012; Qamar et al., 2012; Abiola, 2014; Talib et al., 2014). Tujuan penelitian ini untuk melihat seberapa besar potensi pengembangan sektor pariwisata Pulau Benan Kabupaten Lingga yang berpengaruh terhadap faktor politik, ekonomi, sosial dan teknologi yang terjadi saat ini. Penelitian juga memprediksi potensi pengembangan sektor pariwisata tersebut.

\section{Literature Review}

Model Analisis PEST pertama kali dikemukakan oleh Aguilar (1967) yang mengindentifikasi pengaruh lingkungan terhadap aktivitas bisnis yang meliputi faktor politik, faktor ekonomi, faktor sosial dan teknologi. PEST yang digunakan dalam rangka melihat startegi potensi kebutuhan pasar dikendarai oleh kelompok masyarakat atau unit organisasi. Perkembangan analisis PEST memprediksi situasi dan potensi strategi, masa depan organisasi, perencanaan daya tarik pemasaran atau sebuah ide. Analisis PEST ini dapat dikatagorikan sebagai peluang baik positif maupun negatif terhadap perkembangan di bidang pemasarannya. Hasil penelitian Hasugian, Sukarta, \& Syafariani (2017: 56) menunjukkan bahwa model analisis PEST ditujukan terhadap pertimbangan resiko dan potensi strategi dalam pengelolaan lingkungan eksternal pembangunan wilayah pariwisata di Indonesia.

Mengacu pada Ward \& Peppard, (2002:69) terdapat beberapa faktor yang mempengaruhi model analisis PEST. Faktor-faktor tersebut adalah faktor politik, faktor ekonomi, faktor sosial dan faktor tenologi. Faktor-faktor politik berhubungan dengan bagaimana pemerintah melakukan 
intervensi dalam perekonomian. Secara khusus, faktor-faktor politik memiliki bidang-bidang termasuk kebijakan pajak, hukum perburuhan, hukum lingkungan, pembatasan perdagangan, tarif, dan stabilitas politik. Faktor-faktor politik juga dapat mencakup sebuah program jangka panjang yang ingin disediakan atau disediakan oleh pemerintah (barang-barang pantas) dan barang-barang yang tidak ingin disediakan oleh pemerintah (barang-barang pantas atau barang jelek). Selain itu, pemerintah memiliki dampak besar pada kesehatan, pendidikan, dan infrastruktur suatu negara. Faktor ekonomi termasuk pertumbuhan ekonomi, nilai tukar, tingkat inflasi, dan suku bunga. Faktor-faktor ini sangat memengaruhi cara bisnis beroperasi dan mengambil keputusan. Sebagai contoh, suku bunga mempengaruhi biaya modal perusahaan atau investasi industri, oleh karenanya sejauh mana bisnis tumbuh dan berkembang. Nilai tukar dapat memengaruhi biaya ekspor barang dan penawaran serta harga barang impor dalam suatu ekonomi.

Faktor sosial meliputi aspek budaya dan kesadaran kesehatan, tingkat pertumbuhan populasi, distribusi usia, sikap karier dan penekanan pada keselamatan. Tren tinggi dalam faktor sosial memengaruhi permintaan akan produk perusahaan dan cara perusahaan itu beroperasi. Misalnya, populasi yang menua dapat menyiratkan tenaga kerja yang lebih kecil dan kurang bersedia (sehingga meningkatkan biaya tenaga kerja). Selain itu, perusahaan dapat mengubah berbagai strategi manajemen untuk beradaptasi dengan tren sosial yang disebabkan oleh hal ini (seperti merekrut pekerja yang lebih tua). Faktor teknologi meliputi aspek teknologi seperti aktivitas R\&D, otomatisasi, insentif teknologi, dan laju perubahan teknologi. Ini dapat menentukan hambatan untuk masuk, tingkat produksi minimum yang efisien dan memengaruhi keputusan outsourcing. Selanjutnya, perubahan teknologi akan memengaruhi biaya, kualitas, dan mengarah pada inovasi.

Bagan 1. PEST Analysis Model

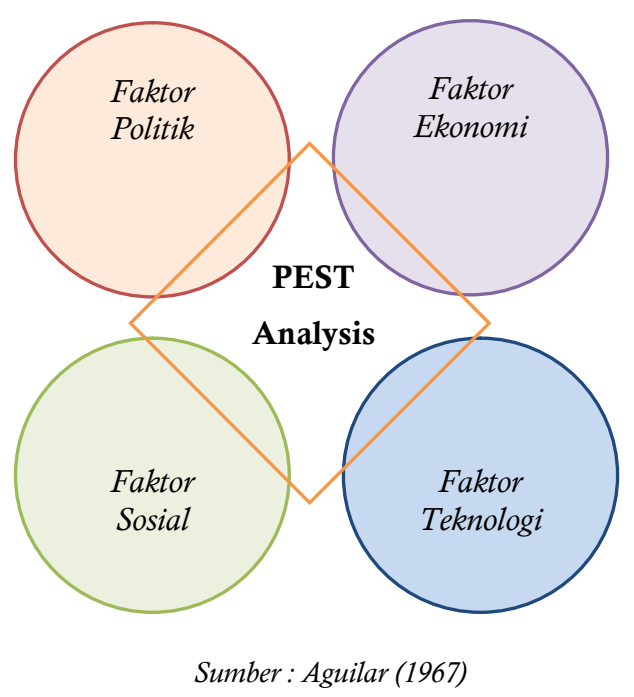

Analisa PEST pada umunya bertujuan untuk mengakaji potensi pertumbuhan yang berorientasi pada dampak pendapatan sebuah objek yang dianalisa sebagai aspek ekonomi marko yang mendukung evaluasi program saat perencaaan, sedang berjalan dan setelah dilakukan demi mengidentifikasi potensi yang akan terjadi (Slamanig, 2012).

\section{Metode}

Metode penelitian yang digunakan adalah studi kepustakaan (library research), dengan melakukan telaah terhadap sumber-sumber pustaka seperti buku-buku, artikel jurnal ilmiah, laporan penelitian, dan dokumen lainnya baik cetak maupun online yang relevan dengan topik yang sedang dikaji 
pada penelitian ini. Studi kepustakaan merupakan serangkaian kegiatan yang berkenaan dengan metode pengumpulan data pustaka, membaca, dan mencatat serta mengolah bahan penelitian (Zed, 2014). Yin (2010) memberikan batasan yang lebih bersifat teknis dengan penekanan pada ciricirinya, Sementara Bogdan \& Biklen (1998) studi kasus merupakan pengujian secara rinci terhadap satu latar atau satu orang subjek atau satu tempat penyimpanan dokumen atau satu peristiwa tertentu.

Ary, Jacobs, \& Razavieh (1985) menjelasankan studi kasus hendaknya peneliti berusaha menguji organisasi atau individu secara mendalam. Kemudian Surakhmad (1980) membatasi pendekatan studi kasus sebagai suatu pendekatan dengan memusatkan perhatian pada suatu kasus secara intensif dan rinci. Pada penelitian ini menggunakan teknik pengumpulan data dokumen yang berasal dari berbagai macam artikel jurnal bereputasi, buku-buku yang berhubungan dengan pengembangan potensi pariwisata. Adapun teknik analisis data pada penelitian ini adalah analisis konten (content analysis).

\section{Hasil dan Pembahasan}

\subsection{Gambaran Umum Pariwisata Pulau Benan}

Pulau Benan merupakan pulau kecil yang terdapat di Kabupaten Lingga dan berada di wilayah administratif Kecamatan Senayang. Letak geografis Pulau Benan membentuk busur kecil yang menghadap ke arah Laut Cina Selatan atau yang sekarang menjadi laut Natuna Utara. Pulau ini berdampingan dengan Pulau Katang dan Pulau Nopong serta Pulau Merodong yang mempunyai luas $190.625 \mathrm{Ha}$ dengan panjang $412.500 \mathrm{M}$. Pada umumnya masyarakat Beban memiliki karakteristik menetap di rumah panggung sepanjang sisi barat pulau. Sebagian besar penduduk Pulau Benan adalah Suku Melayu dan beberapa keluarga Suku Tiong Hoa. Selain menangkap ikan di laut, penduduk Pulau Benan juga membuat keramba ikan dan mengolah hasil laut menjadi bentuk produk pangan lainnya seperti kerupuk ikan, ikan teri kering, cumi kering dan sebagainnya.

Gambar 1. Penyambutan Wisatawan Asing Ke Pulau Benan dalam rangkaWonderfull Sail to Indonesia 2019
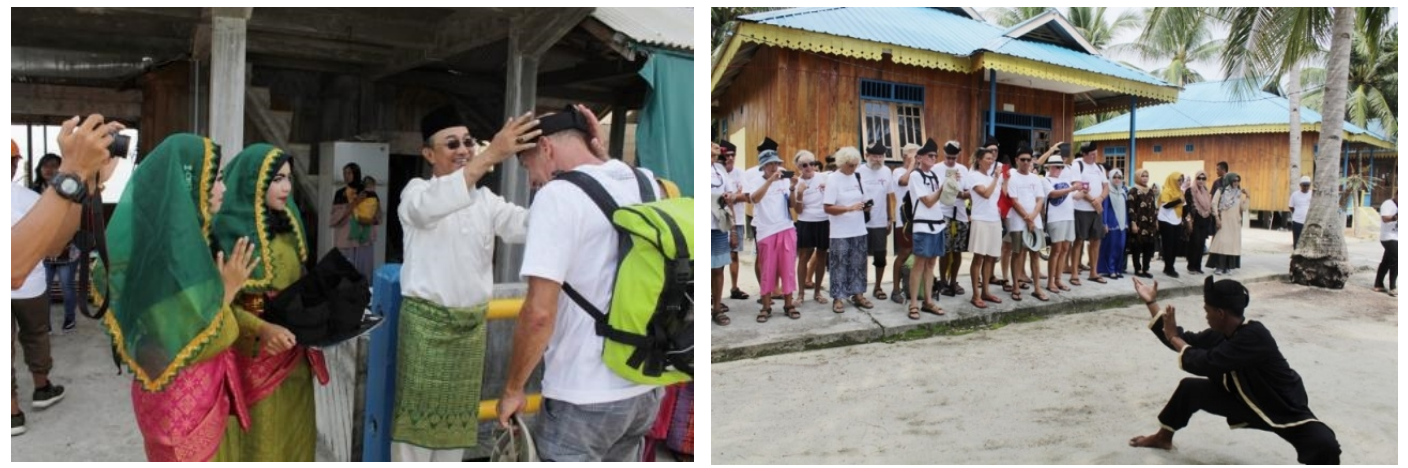

Sumber : Humas Kemenparekraf (2019)

Pada tahun 2015, sebanyak 20 kapal pesiar melabuhkan jangkar di laut Benan baru-baru ini. Kegiatan yang diberi nama "Cruise To Benan Island", ini sedikitnya diikuti oleh 200 orang peserta dari berbagai negara. Mulai dari negara tetangga Singapura, Malaysia, Jepang hingga Amerika, Eropa dan Australia. Wisata bahari, dengan keindahan pantai putih, laut biru yang bersih mempesona tak di sia-siakan para wisatawan. Mulai dari berkeliling melihat pemukiman warga pesisir, snorkling, diving hingga ikut membaur dalam kesenian tradisional masyarakat, yakni Joget Dangkong yang disiapkan oleh pengelola desa wisata Pulau Benan. 
Pulau Benan merupakan tujuan wisata yang populer di kalangan wisatawan. Sajian utama Pulau Benan adalah wisata bahari. Pantai dengan pasir putih dan lautnya biru yang jernih semakin eksotik oleh rindang dan liuknya batang bohon kelapa yang ditiup angin. Dengan ketenangan yang dimiliki pantai Pulau Benan sangat cocok untuk menenangkan pikiran. Ketenangan pantai dan keindahannya nan eksotis, membuat suasana pantai ini terasa tenang dan damai. Kegiatan yang dapat dilakukan di Pulau Benan yaitu menyelam dan snorkeling, karena Pulau Benan memiliki gelombang laut yang tenang. Para wisatawan dapat menikmati hidangan di bawah laut dengan berbagai jenis ikan dan terumbu karang. Selain itu. Bagi wisatawan yang ingin menikmati keindahan melihat bawah laut dan tidak membawa perlengkapan snorkeling, telah disediakan juga persewaan peralatan snorkeling dan juga menyelam.

\subsection{Analisis PEST Pengembangan Potensi Pariwisata Pulau Benan}

Model PEST merupakan analisis terhadap kekuatan eksternal organisasi ataupun di luar dari sebuah program yang dapat mempengaruhi proses hasil yang diinginkan yang meliputi faktor politik, faktor ekonomi, faktor sosial dan teknologi. Dengan mengenali empat faktor tersebut, pengelolaan dalam pengembangan pariwisata di Pulau Benan mampu mendapatkan hasil yang maksimal melalui startegi-strategi yang dianggap tepat sasaran dalam jangka panjang. Adapun hasil analisis model PEST dalam pengembangan potensi pariwisata Pulau Benan adalah sebagai berikut

\subsubsection{Faktor Politik}

Pada dasarnya faktor poltik sebagai strategi yang cukup memungkinkan sebuah wilayah akan mempermudah dalam pembangunan daerah dari sektor pawisata. Di Pulau Benan yang terletak di Kecamata Senayang, APBD di Kabupaten Lingga mengalami defisit padda pada tahun 2014. Sejumlah kegiatan pariwisata di Pulau Benan terkendala dengan adanya pemangkasan sejumlah anggaran terhadap Dinas Budaya dan Pariwisata Kabupaten Lingga. Namun kenyataannya, karena kuatnya faktor politik, anggaran untuk wisata Pulau Benan tidak dipangkas sama sekali. Sejumlah kegiatan yang ada di Pulau Benan terus berjalan sesuai dengan plot anggaran yang telah direncanakan seperti contoh Tour De Benan yang merupakan acara tahunan yang mengunakan APBD Kabupaten Lingga (Tambunan, 2014)

Alasan dipertahankannya kegiatan adalah untuk menjaga citra politik pemimpin daerah. Ketika pemerintah Kabupaten Lingga sukses dalam penyelenggaraan program, maka kemampuan pemimpin daerah akan baik di mata masyarakat. Fasilitas yang di sediakan oleh Dinas Budaya dan Pariwisata Kabupaten Lingga adalah bekerjasama dengan agen travel Kota Batam dan Kota Tanjungpinang. Kemudian menyediakan kapal fery sebanyak 2 unit untuk membawa wisatawan dari Tanjungpinang dan Batam yang sudah mendaftar, menyewa rumahrumah warga yang dijadikan sebagai homestay bagi para wisatawan. Selain itu, juga menyiapkan makan untuk wisatawan sebanyak 2 kali dalam sehari bagi peserta mancanegara dan peserta dari luar Kabupaten Lingga dengan jumlah sebanyak 115 orang peserta selama 2 hari. Untuk penginapan, di Pulau Benan terdapat 6 cottage berkapasitas 10 orang. Dinas jiga menyiapkan homestay dengan menggunakan rumah warga untuk ditempati para wisatawan yang datang.

Selain untuk citra, faktor politik terhadap pariwisata sangat kuat pengaruhnya demi mempertahankan potensi pariwisata Pulau Benan agar dikenali oleh dunia. Selain itu, Pendapatan Asli Daerah (PAD) yang masuk ke Kabupaten Lingga meningkat dari pada pihak kecamatan ataupun desa yang ada di Pulau Benan. Hal ini terlihat jelas bahwasanya program Tour De Benan yang menjadi pejabat PPTK adalah Dinas Budaya dan Pariwisata Kabupaten Lingga. Seharusnya pihak Dinas memberikan pengelolaan dan pengembangan secara utuh dalam mengelola dan mengembangkan pariwisata yang ada di Pulau Benan. Mengelola dan mengembangkan pariwisata yang dimaksud ialah mulai dari sistem manajemen pengelolan, 
pemberdayaan masyarakat tempatan, dan memperhatikan faktor lingkungan yang akan berdampak terhadap potensi sumber daya alam yang seharusnya memiliki konsep pariwisata berkelanjutan.

Potensi faktor politik lainny adalah keberlanjutan program Tour De Benan yang akan selalu menjadi program prioritas utama bagi pemeritah Kabupaten Lingga. Apalagi pada saat ini, di Indonesia telah menyebar wabah COVID-19, pemerintah Kabupaten Lingga akan mencari langkah strategis lain dalam membangkitkan lagi sektor Pariwisata, salah satunya Pulau Benan. Pulau ini memiliki daya tarik yang diminati oleh wisatawan mancanegara.

\subsubsection{Faktor Ekonomi}

Pulau Benan. Sebagaimana dikutip garta.com dalam pemberitaannya, Panca (2019) menjelaskan bahwa PT. Angkasa Wijaya Group (AWG) melakukan investasi di Pulau Benan Kabupaten Lingga sebesar 559, 8 miliar dengan luas wilayah industri pariwisata yang akan dibangun sebesar 78,58 Ha. Penandatanganan komimen investasi dengan pemerintah Kabupaten Lingga dilakukan demi mendorong pertumbuhan ekonomi dalam persaingan ekonomi global. Adapun kerjasama yang sangat penting berada dalam pengelolaan investasi dibawah naungan Dinas Penanaman Modal dan Pelayanan Terpadu Satu Pintu Perdagangan (DPMPTSPP) Kabupaten Lingga. Adapun syarat yang diajukan oleh pemerintah Kabupaten Lingga adalah 3 poin, yaitu melibatkan masyarakat setempat, bekerjasama dengan badan usaha milik dareah (BUMD) Kabupaten Lingga dan memperhatikan kondisi lingkungan agar tetap lestari.

Analisa dari faktor ekonomi yang terjadi adalah perlu adanya pengawasan yang jelas dan terstruktur, kendala bisa diselesaikan agar investasi industri pariwisata dapat tercapainya perekonomian yang lebih baik. Apabila tanpa adanya badan pengawas, maka regulasi dan kemitraan sesuai target dan sasaran investasi akan berdampak pada iklim investasi tersebut. Kemudian anggaran dalam pembangunan infrastruktur harus mempunyai dampak jangka panjang serta kebutuhan pariwisata Pulau Benan dengan mengutamakan skala prioritas. Skala prioritas yang dimaksud yaitu penggunaan anggaran yang ekonomis atau efesien agar kemanfaatan dalam pengembangan pembangunan industri pariwisata di Pulau Benan harusnya tepat sasaran. Sehingga pemberdayaan masyarakat Pulau Benan memiliki peran penting agar terciptanya kesejahteraan masyarakat yang berkelanjutan.

Identifikasi dari peneliti potensi faktor ekonomi yang akan terjadi adalah industri pariwisata Pulau Benan secara positif akan meningkatnya perekonomian pekerja sektor informal yaitu UMKM dan pegiat industri pariwisata yang mengedepankan ekonomi kreatif seperti adanya gerai wisata yang menghasilkan pendapatan UMKM masyarakat Pulau Benan. Meningkatnya potensi faktor ekonomi merupakan dorongan partisipasi masyarakat sebagai aktor penentu perekonomian pariwisata Pulau Benan. Produktivitas masyarakat Pulau Benan harus dijaga agar keberlangsungan industri pariwisata dengan menjaga kualitas hingga kuantitas infrastruktur pariwisata sesuai kebutuhan demi kenyamanan wisatawan berkunjung di Pulau Benan. Wisatawan yang hadir pun tidak ragu akan mengeluarkan biaya untuk insentif pariwisata Pulau Benan karena mereka disajikan pelayanan dan fasilitas yang diinginkan.

\subsubsection{Faktor Sosial}

Faktor sosial merupakan faktor yang dipengaruhi oleh orang-orang di sekitar. Peneliti telah mengidentifikasi faktor sosial yang terdapat di Pulau Benan. Saat ini yang terjadi berdasarkan analisis peneliti terjadi perubahan sosial dimana peran masyarakat terhadap pariwisata Pulau Benan kecataman Katang Bidare telah ikut berpartisipasi memberikan pendapatnya melalui musyawarah rencana pembangungan (Musrembang) tingkat kecamatan Katang Bidare di Pulau Benan. Berdasarkan partisipasi warga tersebut, program unggulan yang diajukan oleh masyarakat di kecamatan Katang Bidare adalah pariwisata Pulau Benan (Aulia, 2020). Kecamatan Katang Bidare memprioritaskan sektor pariwisata karena masyarakat menginginkan 
penjagaan budaya sosial sesuai dengan kebutuhan pariwisata Pulau Benan dengan tetap menjaga kultur "Bunda Tanah Melayu" dengan melihat serta mengantisipasi beberapa ancaman yang muncul. Seperti halnya ketika modal sosial dalam aktivitas kunjungan wisatawan yang hadir ke Pulau Benan memiliki sikap, dan pola prilaku dengan budaya kebaratan. Dampak yang akan terjadi adalah masyarakat harus mengedukasikan berupa sosialisasi dan edukasi akan kultur melayu yang diberikan dalam kapasitas dan etika yang baik.

Faktor budaya yang memiliki potensi jangka panjang akan muncul yaitu adanya program wisata halal bagi pengunjung wisatawan asing. Meskipun nantinya terdapat pro dan kontra dari berbagai pihak yang mempunyai kepentingan terhadap pariwisata di Pulau Benan tersebut, pastinya harus menghadirkan solusi yang baik. Artinya, hal yang di anggap wajar dalam sikap serta pola prilaku wisatawan yang hadir ke Pulau Benan tersebut harusnya mengikuti aturan serta budaya sosial yang selama ini dijaga oleh masyarakat Pulau Benan. Konsep wisata halal ini sebagai upaya mengantisipasi hal-hal dari kegiatan yang merusak dari nilai-nilai pariwisata sehingga semua yang berpartisipasi dalam aktivitas kepariwisataan bisa mendapatkan tujuan awal pariwisata Pulau Benan. Di sisi positifnya, potensi yang akan terjadi yaitu banyaknya kultur budaya melayu kabupaten lingga yang akan diedukasikan kepada wisatawan asing yang datang di Pulau Benan. Karena Melayu adalah identitas yang kuat dengan adat istiadat kerajaan melayu yang dijaga dengan memegang pepatah "Tak Kan Melayu Hilang Di Bumi".

\subsubsection{Faktor Teknologi}

Pada prinsipnya perkembangan zaman akan membutuhkan teknologi. Faktor teknologi kepariwisataan sangan dibutuhkan sebagai upaya promosi destinasi wilayah yang memiliki keindahan dan masih alami lingkungannya. Kebutuhan teknologi di Pulau Benan saat ini yang bisa diidentifikasi adalah media masa. Peneliti menemukan banyaknya pemberitaan tentang Pulau Benan yang identik dengan wisatanya. Hal ini terbukti dari beberapa media masa yang mengungkapkan banyaknya wisatawan yang berkunjung ke Pulau Benan. Berdasarkan google trend yang di telusuri oleh peneliti, dunia mencoba mengakses informasi dengan hasil tangkapan layar berikut ini :

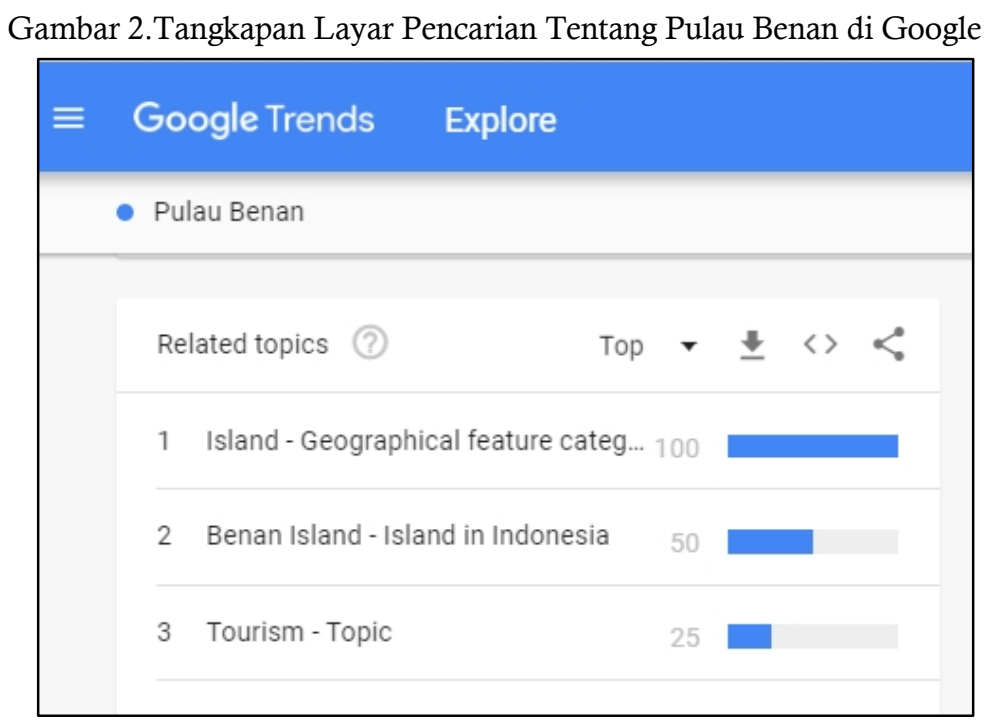

Sumber: Google Trend 2020

Pulau Benan memilki ketertarikan di penjuru dunia, sebagaimana diketahui sebanyak 20 negara pernah berkunjung ke Pulau Benan dalam kegiatan Sail To Indonesia 2019. Kemudian fasilitas teknologi yang ada di Pulau Benan dalam mendukung pariwisata, peneliti belum 
menemukan penggunaan fasilitas teknologi yang mendukung kepariwisataan tersebut. Keterbatasan oleh peneliti membuat sulit mendapatkan data primer maupun sekunder teknologi apa saja yang telah diterapkan dalam pengembangan pariwisata yang ada di Pulau Benan.

Identifikasi terhadap teknologi yang ada dalam proses jangka panjang adalah jaringan komunikasi dan teknologi berbasis 4.0 seperti fasilitas internet. Sebagaimana diketahui, Pulau Benan memiliki akses yang sangat jauh dari pusat ibu kota di Kabupaten Lingga. Oleh karena itu potensi jaringan teknologi dan teknologi pendukung lainnya akan menjadi fokus utama dari pelayanan publik, seperti akses manajemen paket wisata yang bisa terkoneksi dari semua platform yang menghubungkan kebutuhan pariwisata berbasis teknologi maupun informasi.

\subsection{Penerapan Model Skala Prioritas Potensi Pengembangan Pariwisata}

Skala prioritas dengan tujuan melakukan pemetaan potensi yang akan terjadi di masa yang akan datang, mulai dari produktifitas dan kesejahteraan masyarakat menjadi skala prioritas dimana aktor memulai dengan melihat dan mempersiapkan kapasitas pengembangan parawisata. Selanjutnya, aktor-aktor tersebut berupaya mengidentifikasi potensi pariwisata dengan menyandingkan dua jenis prinsip kapasitas pengembangan pariwisata, yaitu aturan atau regulasi serta mitra dan investasi. Pemerintah daerah melakukan kerjasama dengan pengelola pariwisata, baik dibawah naungan BUMD (Publik) ataupun Perusahaan Industi Pariwisata (Private) dengan membuat kesepakatan dengan mengunggulkan skala prioritas Potensi Pariwisata.

Bagan 4. Model Skala Prioritas Potensi Pengembangan Pariwisata di Fokuskan Pulau Benan, Kabupaten Lingga

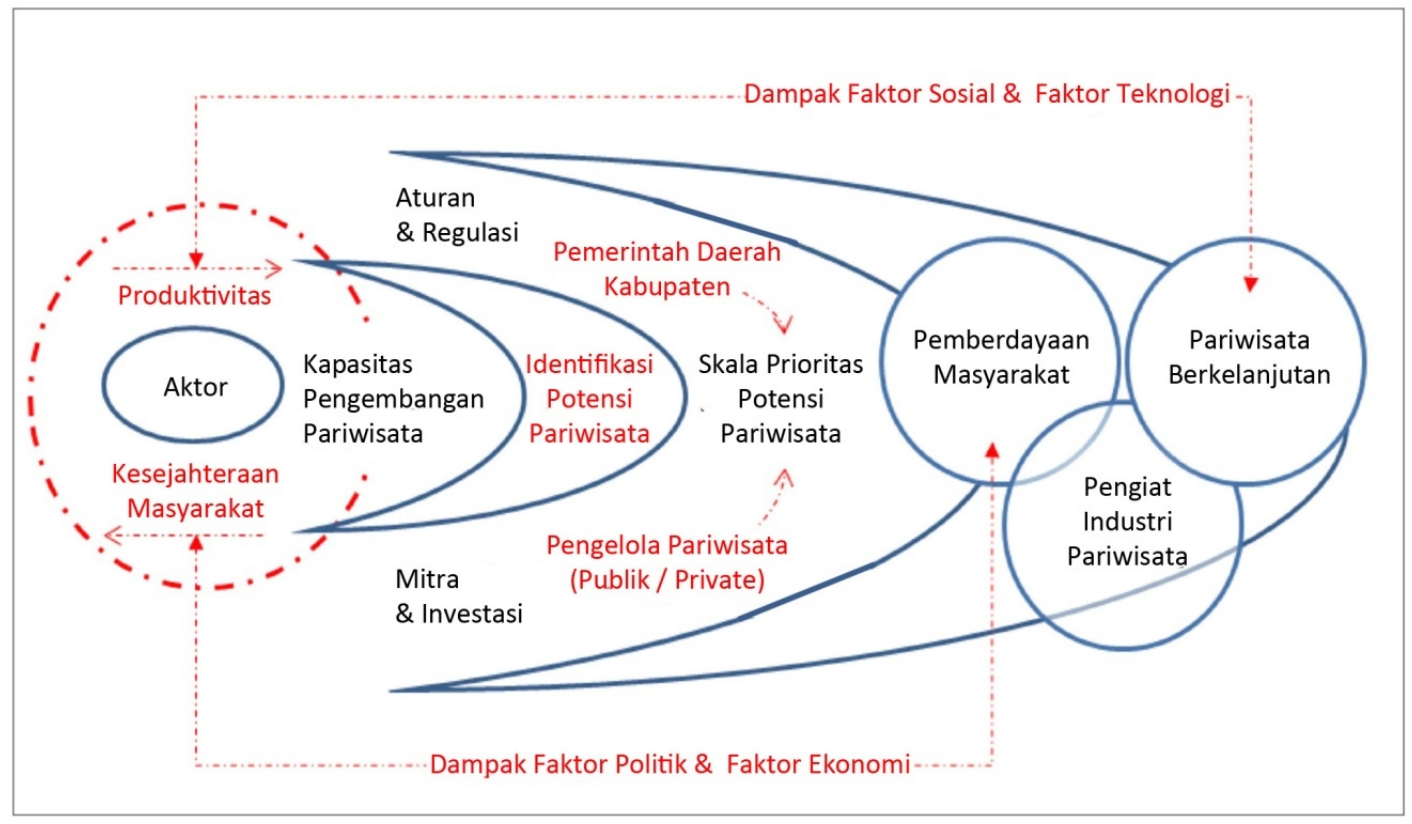

Sumber: Olahan Peneliti Adopsi dari Kelly, Kelliher, Power, \& Lynch (2020)

Kemudian peneliti mengkasifikasikan analisis PEST model menjadi dua yaitu dampak PE dan Dampak ST. Pengklasifikasan model ini dengan alasan tujuan model skala prioritas potensi pengembangan pariwisata yang diharapkan sesuai dengan fokus yang berbeda sebagai pembagian yang lebih efektif jika analisis PETS ini masih digabungkan. Dampak PE hanya memfokuskan dirinya terhadap produktifitas yang nantinya mencapai tujuan terhadap pariwisata berkelanjutan, dengan tujuan produktifitas aktor dapat mempertahankan pariwisata dengan jangka waktu yang panjang. Begitu juga dengan Dampak ST, aktor lebih difokuskan kepada kesejahteraan 
masyarakat di dalam prosesnya nanti, maka aktor yang mencapai tujuan mempertahankan pemberdayaan masyarakat di Pulau Benan.

Dampak PE dan dampak ST ini saling berkaitan dengan pegiat industri pariwisata. Tanpa pegiat industri pairiwisata tidak akan memiliki tujuan yang jelas karena promotor kepariwisataan adalah adanya penggerak dari pegiat industri pariwisata. Pegiat industri pariwisata bisa muncul dari pemangku kepentingan yang ada seperti pemerintah pusat, pemerintah daerah, para pengusaha dan orang yang ingin memberikan kontribusi terhadap pariwisata di indonesia. Pemberlakuan model ini tergolong baru untuk melihat pengunaan model yang cocok terhadap pariwisata yang diterapkan di pulau-pulau dengan kondisi berbeda dengan pariwisata di perkotaan maupun perdesaan yang tidak memiliki masalah yang komplit.

\section{Penutup}

Model analisis PETS serta model skala prioritas potensi pengembangan pariwisata yang difokuskan ke Pulau Benan Kabupaten Lingga hanya mengonfirmasi dan mengidentifikasi berbagai hal yang akan terjadi melalui tahap dan proses analisis yang berdampak pada kepariwisataan di Indonesia. Hasil dan pembahasan tentang pengembangan potensi pariwisatan Pulau Benan seharusnya menjadi tolak ukur bagaimana memprediksi dampak positif dan dampak negatif dengan mempengaruhi faktor politik, faktor ekonomi, faktor sosial dan faktor teknologi yang mempengaruhi lingkungan sebuah objek yang dianalisis.

Pariwisata Pulau Benan pada dasarnya memiliki banyak sekali pengembangan potensi yang harus difokuskan karena tergolong baru dalam 10 tahun terakhir. Akan tetapi perlu juga diperhatikan tidak semua pariwisata yang ada di indonesia berjalan dengan baik dalam pengelolaannya. Untuk Pulau Benan Kabupaten Lingga, peneliti memiliki dua point rekomendasi yang harus dilakukan oleh pemangku kepentingan dalam pengembangan sektor pariwisata Pulau Benan di Kabupaten Lingga. Pertama, Segera membentuk Badan Satuan Tugas Percepatan Pariwisata Kabupaten Lingga. Hal ini diperlukan dalam mengantisipasi beberapa kendala yang belum muncul dalam pembahasan model analisis PETS pariwisata pulau benan. Selain mengatisipasi, Badan satuan tugas ini mempunyai hak dan wewenang memberantasi oknum yang ingin mengagalkan, merusak dan mengambil keuntungan individu dari sektor pariwisata Pulau Benan di luar masyarakat Pulau Benan tanpa seizin dari pengelolaan pariwisata sesuai aturan dan ketentuan kemitraan dan investasi industri pariwisata.

Kedua, memperkuat Collaborative Governance dalam rangka mempercepat proses pembangunan infrastruktur, program ekonomi kerakyatan, program kebudayaan dan program pengembangan teknologi dengan mengajukan sebuah permohonan ke pemerintah pusat yang bisa dipersiapkan untuk program jangka panjang. Empat komponen tersebut perlu karena pariwisata tidak cukup dengan partisipasi masyarakat, pihak swasta dan pemerintah daerah,. peran pemerintah pusat sangat diperlukan karena keterbatasan anggaran dalam proses pembangunan kepariwisataan di Pulau Benan Kabupaten Lingga.

\section{Acknowledgement}

Penulis mengucapkan terima kasih kepada Camat Katang Bidare, Kabupaten Lingga serta wartawan kabupaten lingga yang telah memberikan informasi tentang pemberitaan pariwisata di Pulau Benan Kabupaten Lingga. Tak lupa temen diskusi beberapa dosen Magister Ilmu Administrasi Publik, Universitas Brawijaya sehingga dapat dituangkan dalam bentuk tulisan agar dapat dibaca secara potensi pariwisata di Pulau Benan Kabupaten Lingga.

\section{Funding}

Tulisan ini ditulis dengan data yang diperoleh melalui studi literatur dan tidak menerima pendanaan dari pihak pemerintah Kabupaten Lingga maupun pihak swasta. 


\section{Conflicts of Interest.}

Penulis menyatakan artikel ini tidak memiliki conflicts of interest

\section{References}

Abiola, J. (2014). The Impact of Information and Communication Technology on Internal Auditors' Independence: A PEST Analysis of Nigeria. Journal of Scientific Research and Reports, 3(13), 1738-1752. https://doi.org/10.9734/JSRR/2014/9634

Aguilar, F. (1967). Scanning the business environment. New York: Macmillan.

Akhirman, \& Nurhasanah. (2019). Strategi pengembangan pariwisata bahari di Desa Pulau Benan Kecamatan Senayang Kabupaten Lingga. Bahtera Inovasi, 2(2), 76-87.

Anggita, K. (2020). Pariwisata Indonesia terancam kehilangan Rp7,7 Triliun karena Korona.

Arfandi, \& Adhayanto, O. (2017). Kebijakan pengembangan pariwisata berbasis kemaritiman : Studi pada Kabupaten Kepulauan Anambas. KEMUDI : Jurnal Ilmu Pemerintahan 1(2), 104-117.

Ary, D., Jacobs, L. C., \& Razavieh, A. (1985). Introduction to research in education (3rd ed.). New York: Holt, Rinehart, and Winston.

Aulia. (2020). Musrenbang Pulau Benan, Kecamatan katang bidare ajukan Pariwisata jadi program unggulan.

Bachri, T. B. (2018). Kelemahan pariwisata Indonesia.

Bintang. (2020). Isdianto yakin industri pariwisata Kepri semakin maju.

Bogdan, R. C., \& Biklen, S. K. (1998). Quality research for education: An introduction to theory and methods (3rd ed.). Boston: Allyn and Bacon.

Firdaus, F. (2018). Potency of Integrated Cultural Tourism Development at Maninjau Lake Area, West Sumatera. Mimbar: Jurnal Sosial Dan Pembangunan, 34(1), 72-82.

Ha, H., \& Coghill, K. (2008). E-government in Singapore: A SWOT and PEST analysis. AsiaPacific Social Science Review, 6(2), 103-130.

Hasugian, L. P., Sukarta, S., \& Syafariani, R. F. (2017). Analisis pembangunan sistem informasi pengelolaan lingkungan bebas sampah terintegrasi di wilayah pariwisata Indonesia. Jurnal ULTIMA InfoSys, 8(2), 54-61.

Hengky, S. H., \& Kikvidze, Z. (2018). Tourism sustainability in the Bogor Botanical Gardens, Indonesia. Urban Forestry and Urban Greening, 30(January), 8-11.

Karlina, T., \& Iskandar, I. (2017). Upaya Indonesia meningkatkan jumlah kunjungan wisatawan mancanegara di Kepulauan Riau. Jurnal Online Mahasiswa Fakultas Ilmu Sosial Dan Ilmu Politik, 4(2), 1-11.

Kelly, N., Kelliher, F., Power, J., \& Lynch, P. (2020). Unlocking the niche potential of senior tourism through micro-firm owner-manager adaptive capability development. Tourism Management, 79(12), 1-6. https://doi.org/10.1016/j.tourman.2020.104081

Kurniawan, F., Adrianto, L., Bengen, D. G., \& Prasetyo, L. B. (2019). The social-ecological status of small islands: An evaluation of island tourism destination management in Indonesia. Tourism Management Perspectives, 31, 136-144. https://doi.org/10.1016/j.tmp.2019.04.004

Marina, H. (2012). Ekonomi politik Pariwisata kawasan wisata lagoi Kabupaten Bintan. Jurnal Fakultas Ilmu Sosial Dan Ilmu Politik.

Nadjmi, N., \& Prayitno, B. (2013). Pulau Batam sebagai kawasan destinasi wisata terpadu di Kepulauan Riau. FT UGM, 1-9.

Nofrizal. (2015). Analisis strategi bersaing gudang digital yogyakarta dalam memperluas pasar. Jurnal Ilmiah Ekonomi Dan Bisnis, 12(2), 247-261.

Nuzululita, L., Purba, N. A. U., Prasetya, K., \& Amelinda, D. (2020). Pengaruh brand wonderful Indonesia dalam pembangunan industri pariwisata Indonesia. Student Journal of Management, (2), 1-14.

Panca, R. (2019). Kembangkan pariwisata, Pemkab Lingga gaet investasi Rp599 M di Pulau Benan.

Qamar, S., Jan, S., Hasan, L., \& Memon, L. A. (2012). E-government in Pakistan: SWOT and PEST analysis. Sindh University Research Journal (Science Series), 44(4), 587-592. 
Retnowati, N. D. (2010). Analisis lingkungan internal dan eksternal studi kasus PT intan pariwara klaten. Jurnal Buana Informatika, 1(2), 91-96.

Sari, D. P., Handayani, N. U., Widharto, Y., Ridho, K. H., Senamelia, S., Aulia, F. S., \& Ardiyawan, R. (2019). Analisis manajemen dan potensi risiko mengunakan PEST analysis dan risk mapping di kampung batik semarang. In Prosiding Industrial Engineering National Conference (IENACO) IENACO (Industrial Engineering National Conference) 72019 (pp. 437444). Surakarta: Universitas Muhammadiyah Surakarta.

Siam, N. U. (2015). Peran dinas kebudayaan dan pariwisata Kabupaten Lingga dalam pengembangan objek wisata. Jurnal Ipteks Terapan, 8(4), 210-221.

Slamanig, M. (2012). PEST analysis hungary: Country Evaluation and selection of Hungary. Austria: GRIN Verlag.

Stosic, I., Nikolic, D., \& Zdravkovic, A. (2012). PEST Analysis of Serbia. Economic Analysis, 45(1-2), 59-73.

Surakhmad, W. (1980). Pengantar penelitian ilmiah: dasar, metode dan teknik. Bandung: Tarsito.

Talib, M. S. A., Hamid, A. B. A., Zulfakar, M. H., \& Jeeva, A. S. (2014). Halal logistics PEST Analysis: The Malaysia Perspective. Asian Social Science, 10(14), 119-131. https://doi.org/10.5539/ass.v10n14p119

Tambunan, M. (2014). APBD defisit, proyek Tour De Benan jalan terus.

Thariqy, I. W., Pristiwasa, K., \& Hakim, M. F. N. (2019). Pengembangan potensi pariwisata natuna sebagai daya tarik geowisata di Kepulauan Riau. Jurnal Kepariwisataan Dan Hospitalitas, 3(2), 156-161.

Thomas, V. F. (2019). Menteri Luhut : Pariwisata penyumbang devisa paling menjanjikan di masa depan.

Tiara, T. P., \& Darsiharjo. (2013). Analisis potensi pariwisata di pulau Karimun provinsi Kepulauan Riau. In Seminar Nasional Pendayagunaan Informasi Geospatial Untuk Optimalisasi Otonomi Daerah (pp. 138-143). Surakarta: Universitas Muhammadiyah Surakarta.

Ward, J., \& Peppard, J. (2002). Strategic planning for information systems (3rd ed.). United Kingdom: Wiley.

Widagdyo, K. G. (2015). Analisis pasar pariwisata halal Indonesia. The Journal of Tauhidinomics, $1(1), 73-80$.

Widhasti, G. B., Damayanti, C., \& Sardjono, H. S. (2017). Diplomasi publik pemerintah republik Indonesia melalui pariwisata halal. Solidaritas : Jurnal Ilmullmu Sosial, 1(1), 1-13.

Yin, R. K. (2010). Qualitative research from start to finish. New York: Guilford Press.

Yoserizal, \& Yudiatmaja, W. E. (2010). Strategi Pemerintah Provinsi Sumatera Barat dalam mengembangkan e-government sebagai upaya peningkatan kualitas pelayanan publik. JIANA (Jurnal Ilmu Administrasi Negara), 10(1), 89-100.

Zed, M. (2014). Metode penelitian kepustakaan (3rd ed.). Jakarta: Yayasan Obor Indonesia. 